\title{
NASA DIRECTIONS IN SPACE PROPULSION FOR 2000 AND BEYOND
}

\section{NASA TM 102281}

Gregory M. Reck, Director

Propulsion, Power \& Energy Division

National Aeronautics and Space Administration

(EASA-TH-102281) HASA CIBECTICIS IE SPACE EEOPUISION FCE $20 C O$ ANC BEYCAL (WASA) 12 p

$889-21026$

$$
\text { CSCL } 21 \mathrm{H}
$$

Declas

$63 / 20$

0200060

SYMPOSIUM ON SPACE COMMERCIALIZATION:

ROLES OF DEVELOPING COUNTRIES

MARCH 5-10, 1989/NASHVILLE, TN 


\title{
NASA DIRECTIONS IN SPACE PROPULSION FOR 2000 AND BEYOND
}

\author{
Gregory M. Reck \\ NASA Headquarters \\ Washington, DC 20546
}

\begin{abstract}
In his National Space Policy of 1988 , President Reagan committed to a goal of expanding human presence and activity in the solar system. This goal has provided the impetus for a resurgence of activity across a broad range of space technology efforts in general and for a number of propulsion technology programs in particular. Building on recommendations from several detailed studies of the U.S. space program, NASA has increased the level of investment in propulsion technology development. The Civil Space Technology Initiative is developing propulsion technology in support of near-Earth operations. These efforts are focused on both main and booster engines and seek to provide design methods and data bases to support future developments of low cost, reliable transportation systems. Program elements include turbomachinery, combustion systems, and condition monitoring and diagnostics, and the design methodology developed at component levels will be verified in large scale systems. The Pathfinder Program is developing a suite of technologies to enable a broad range of manned and unmanned missions beyond Earth's orbit. These include both chemical and electric propulsion technologies to support potential missions to the Moon and Mars.
\end{abstract}

\section{INTRODUCTION}

A spectrum of exciting new space opportunities have been identified which will place significant new demands on propulsion systems. These range from low cost, high thrust booster engines for launch vehicles to high performance, low thrust engines for cargo transfer vehicles. Propulsion system technologies needed to support these missions are identified and several ongoing NASA technology programs are described which are structured to provide the design tools and data bases needed to design these propulsion systems in the future.

\section{BACKGROUND}

The Presidential Directive of 1988 on National Space Policy (ref.1) committed to a goal of US leadership which included three major components: (1) expanding human presence beyond Earth orbit into the solar system, (2) creating opportunities in-space for U.S. commerce, and (3) continuing the national commitment to a manned space station. These important and far-reaching goals have set in motion a number of activities within NASA. While the specific strategy to pursue these goals has not yet been fully detailed, several significant studies conducted over the past three years have contributed to an assessment of the state of technology and technology needs if these ambitious goals are to be accomplished.

The report of the National Commission on Space (ref. 2) published in 1986 offered a tantalizing vision of the possibilities for the next 50 years in space. The commission proposed a future-oriented civil space program to advance scientific understanding of space, explore the Solar System, and stimulate space enterprises for the benefit of people on Earth. To accomplish these thrusts they recommended a longrange commitment to advance a broad spectrum of technologies for critical capabilities, and to create and operate systems and institutions to provide low-cost access to the Solar System.

Subsequently, the NASA Administrator formed a task group, led by Dr. Sally Ride to define potential U.S. space initiatives, and to evaluate them in light of the current space program and the nation's desire to regain and retain space leadership. The objectives of the 
study were to energize a discussion of the longrange goals of the civilian space program and to begin to investigate overall strategies to direct that program to a position of leadership. In her final report, (ref. 3) Dr. Ride identified four candidate missions which included (1) Mission to Planet Earth, (2) Exploration of the Solar System, (3) Outpost on the Moon, and (4) Humans to Mars. An assessment of the current space program was also conducted which identified Earth-to-orbit transportation as NASA's most pressing problem from now until the mid-1990's.

The National Research Council through the Aeronautics and Space Engineering Board conducted an evaluation of the U.S. advanced space technology requirements for the next 30 years, and recommended a technology development program for an aggressive civil future in space. The report of this evaluation, published in 1987 (ref. 4) found the level of investment inadequate and recommended no less than $7 \%$ of the total NASA budget be allocated to several key technology areas. "Advanced propulsion research and development should be afforded the highest priority ... and a new generation of technology should be pursued to support U.S. launch requirements." Specifically, the report recommended that NASA pursue (1) a range of advanced Earth-toorbit engines, (2) reusable cryogenic orbit transfer engines, (3) high thrust and/or high performance space transfer engines, and (4) high performance, low thrust primary engines for space exploration.

\section{FUTURE OPPORTUNITIES}

In response to the early study efforts, the Office of Exploration (OEXP) was established in 1987 to provide recommendations and alternatives for an early 1990's national decision on a program of human exploration of the Solar System. The office also has the charter to steer agency investigations toward providing technology choices for a potential mission decision. OEXP has undertaken an extensive, agency-wide study to accomplish these objectives.
The method used by OEXP involves the identification of reference missions or "case studies." These are identified not with the intention of selecting one case in preference to the others, but rather of isolating and identifying potential requirements and sensitivities that influence the complexity, feasibility and benefits of each candidate mission. Four case studies were developed by OEXP during 1988 as follows: (1) Human Expedition to Phobos, (2) Human Expeditions to Mars, (3) Lunar Observatory, and (4) Lunar Outpost to Early Mars Evolution. As a result of the first year of study of these cases, a number of insights regarding both specific aspects as well as strategic technology implications have been gained and these are detailed in reference 5.

The initial study results clearly reinforce that a dependable, high performance Earth orbit transportation capability is of fundamental importance to the success of any exploration initiative. The studies also indicate that the definition and selection of Earth-to-orbit launch capability to support the exploratory mission s cannot be considered separately from the capability provided for low-Earth orbit assembly and operations. At least several of the cases are critically dependent on the in-space assembly of large vehicle and payload structures.

Several space transfer propulsion technologies were identified with high potential leverage (savings or benefits if incorporated) for some of the cases. These included low-thrust electric propulsion for cargo transfer and also nuclear thermal rocket technology as an alternative to chemical propellants for high thrust requirements. The studies have also clearly indicated the large benefits associated with the in situproduction of propellants on the lunar or planetary surface.

\section{PROPULSION TECHNOLOGY IMPLICATIONS}

Without exception, the studies noted previously emphasize the dependence of future U.S. space efforts on reliable, low-cost transportation capabilities. Detailed transportation system architecture studies have highlighted the need for 
a mix of launch vehicles in the future. These include unmanned heavy-life cargo launch vehicles, as well as manned transport vehicles equipped for launch and return of personnel and compact, high value cargo. For cargo transport, the Advanced Launch System (ALS) represents the next generation with a goal of reducing the transportation cost to LEO to onetenth of present day costs. While the ALS configuration has not been selected, current studies are examining a range of core and booster engines which may use either liquid oxygen (LOX) and hydrogen, or LOX and hydrocarbon fuels. The systems may be expendable or partially reusable. The propulsion needs include low cost, reliability, flexibility, low environmental impact and adequate performance. Propulsion designers will also aim for generous design margins and features to minimize prelaunch operations.

For manned launch systems, the Space Shuttle will continue to support launch requirements in the near term. However, the approach to the next generation of improved, lower cost vehicles is not clear. Several alternatives could include an evolution of the basic shuttle configuration by incorporating advanced systems, a personnel carrier with largely expendable stages, or a new advanced manned launch system which might be either single or two stage, including reusable or partially reusable systems. Propulsion system needs vary depending on the path selected, but will include reliability, low cost, reusability, low environmental impact and high performance. Design margins will also be an important feature, and health monitoring and diagnostic systems will be incorporated to minimize operations costs.

Future space transfer propulsion engines will be required to support a variety of space missions. These include the continued need for low cost transfer between LEO and Geosynchronous Earth Orbit (GEO), as well as the requirements associated with the new exploration missions under consideration. Man-rating and/or reusability requirements are likely to dictate high reliability and large design margins. Hydrogen-oxygen engines will be needed to minimize the propellant weight required in LEO to accomplish the mission. Space-based systems will require main- tenance-free operation and advanced health monitoring systems. If the transfer engines are also used for lunar or planetary descent and ascent, then throttleability will be a requirement.

Several of the exploration case studies include a "split mission" strategy which incorporates a separate cargo vehicle that is launched in advance of the manned mission. The cargo vehicle utilizes electric propulsion which is more efficient than chemical, but with lower thrust, and results in a longer transit time that would be undesirable for a manned mission. The manned vehicle would utilize chemical propellants and would rendezvous with the cargo vehicle in the vicinity of the planet. Candidate electric propulsion systems include ion and magnetoplasmadynamic thrusters.

Many of the propulsion technologies identified above are being addressed in current NASA programs. These include the Civil Space Technology Initiative and Project Pathfinder. These will be described in subsequent sections.

\section{CIVILSPACE TECHNOLOGY INITIATIVE}

The Civil Space Technology Initiative (CSTI) is a first step in a focused effort to develop the technology base for future space missions. The primary emphasis is on efficient, reliable access to, and operations in, low Earth orbit, and on support of science missions from Earth orbit. The objectives of CSTI are to develop specific technologies critical to accomplishment of relatively near-term, high priority national goals. CSTI is directed at important advances in transportation, operations, and science, and it has been organized into these three thrusts (figure 1). Reference 6 contains a more complete description of CSTI.

The transportation element of CSTI addresses those technologies that will provide safe and efficient access to space. It includes two propulsion elements, Earth-To-Orbit (ETO) propulsion which applies to pump-fed, high pressure engines, and Booster propulsion. 


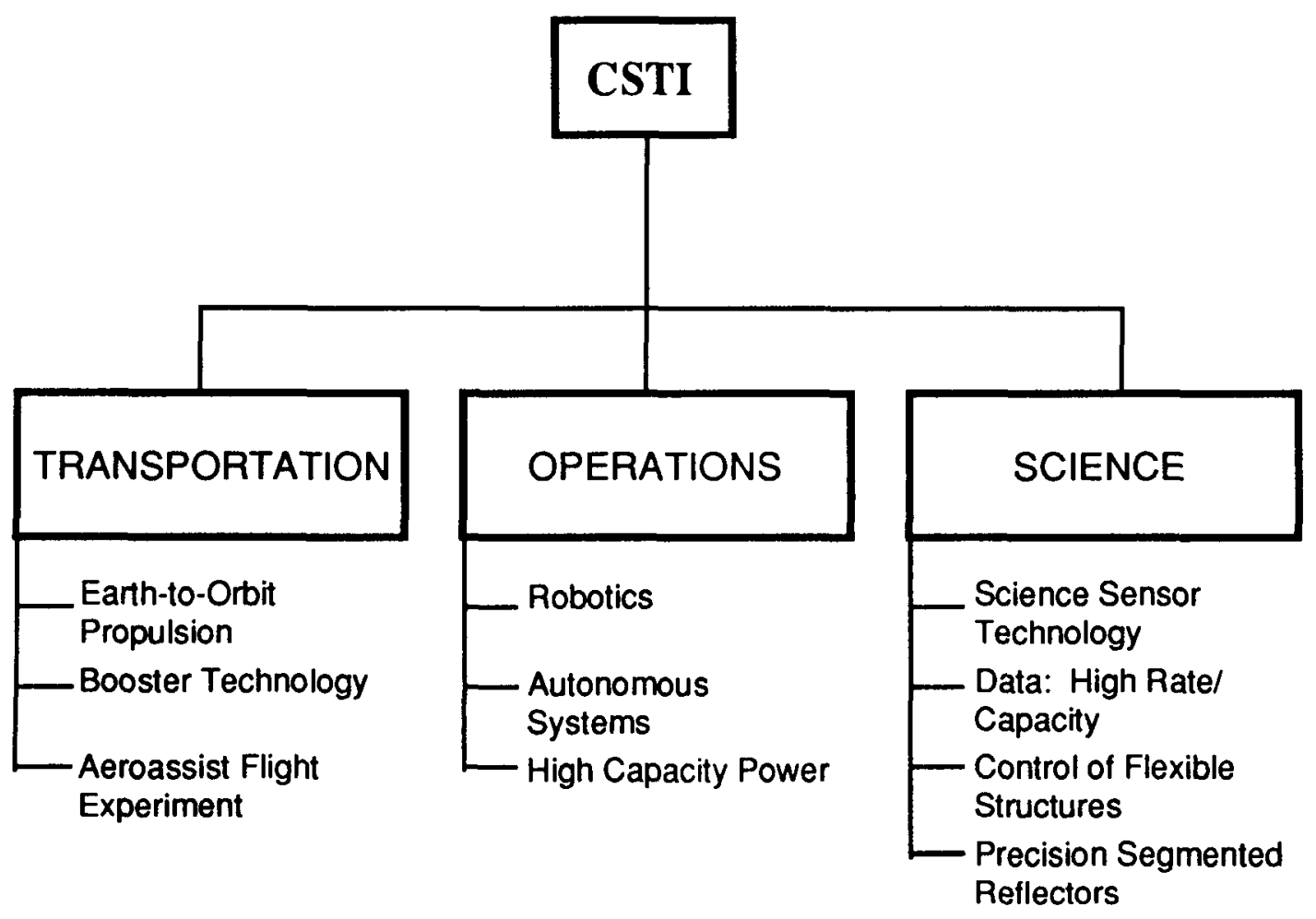

Figure 1. Civil Space Technology Initiative

\section{CSTI Earth-to-Orbit Propulsion}

The goal of the ETO Propulsion Program is to provide a validated technology base necessary to proceed in the 1990's with the development of high performance, long-life, pump-fed engines to operate with either hydrogen or hydrocarbon fuel. The program focuses on extending the knowledge and understanding of rocket engine chemical and physical processes so that realistic analytical simulations of internal environments can be made as well as accurate predictions of steady and unsteady loads, material behavior, structural response, and failure mechanisms. The program also includes technologies for reducing ground operations costs and ensuring safer, more reliable flight operations through the development of on-board integrated health monitoring and control systems. The program consists of two phases: (1) Technology Acquisition, and (2) Technology Verification. Each phase is further organized into Turbomachinery, Combustion Devices and System Monitoring/Controls Elements.
The technical approach is summarized in figure 2. Technology Acquisition provides for the development of new or enhanced analysis and design models and codes using analytical techniques supported by empirical laboratory data. It includes the synthesis of new materials, definition of materials properties, development of new manufacturing and inspection techniques and development of new instrumentation. After proof-of-concept is demonstrated in the acquisition phase, technologies will transition in to the Technology Verification phase. In this phase, technologies are verified in large scale component and subcomponent test beds which provide a realistic engine environment. This may satisfy verification requirements for some technologies, while others may require further testing in an engine system. Engine systems testing will be conducted in a Space Shuttle Main Engine (SSME) Systems Technology test bed. Some technology products from the Technology Acquisition phase may be integrated directly into the SSME test bed without large scale verification as appropriate. 
Technology Acquisition - The major objectives of this phase are to develop fundamental analytical techniques and design concepts at the subcomponent and subscale level. This includes: extending knowledge and understanding of rocket engine chemical and physical processes; developing analytical techniques to perform realistic simulations of internal rocket engine environments; developing design methodologies to accurately predict design margins, performance and operation of engine subcomponents and components; and developing and demonstrating characteristic proof-of-concept of advanced engine subcomponent and component design concepts.

In the area of turbomachinery, analytical models being developed include those to simulate rotor dynamics, bearing characteristics, hot gas flow fields, aerothermodynamic loads, structural response characteristics, and material behavior under high stress operating conditions. From these models, design methodology and life prediction techniques can then be developed. Advanced materials and processes, such as advanced single crystal and fiber reinforced superalloy materials, powder metallurgy, ion implantation, and vacuum plasma coatings are being evaluated for application to bearing, turbine blades, disks and impellers.

For combustion devices, analytical codes for combustion performance, stability, heat transfer and cooling are being extended to high pressure combustion with empirical data for code validation obtained from subscale testing. Primary emphasis is on LOX/hydrocarbon combustion.

In the systems monitoring area, diagnostic sensors have been identified that appear capable of monitoring the condition of critical components. Laboratory tests are being used to verify sensor performance and operation.

Many activities incorporated in the Technology Acquisition phase have been underway for several years. Some early products of these efforts include a damping seal design concept, hollow single crystal turbine blade designs, a thermomechanical model of bearing coolant flow verified on a bearing test rig, and a plume anomaly spectrometer. These technol- ogies have now moved into the verification phase.

Technology Verification - Technologies which have matured from the Technology Acquisition phase will move to the Large Scale Verification element for verification in combustion, turbomachinery, or health monitoring and control devices. Promising turbine, pump, bearing, seal, complex flow path and rotordynamic design concepts from the acquisition element will be used for the design, fabrication and test of new research turbomachinery assemblies. The operating conditions will be close to those expected in advanced engines, and significantly different from the SSME. The test hardware will be capable of operation over a wide range of conditions in order to develop a broader understanding of critical design and operating characteristics. Research quality instrumentation will be utilized and will include the capability to evaluate alternative design concepts.

Combustor and nozzle design concepts and technologies will be validated in combustors. Injector elements will be designed for a large scale combustor, but only a segment of the injector equivalent to about 50,000 lbs thrust will be tested initially. Improvements to the design concepts and analytical models will be made, if necessary, prior to the large scale hardware design and fabrication phase. Some technologies, such as combustion stability, may require further verification in larger scale hardware.

The approach in safety monitoring will be to define the overall system, then integrate appropriate diagnostic sensors with an off-line computer to validate failure detection, isolation, and safe engine shut-down. An overall system design approach to condition monitoring will be defined that will provide more efficient maintenance scheduling, improve life prediction techniques, and quantify risks and trends for next flight readiness assessment.

Condition monitoring logic will be developed including interactions between test algorithms, signal processing models, and a historical data base.

The Engine Systems Technology element is designed to provide verification of the CSTI 


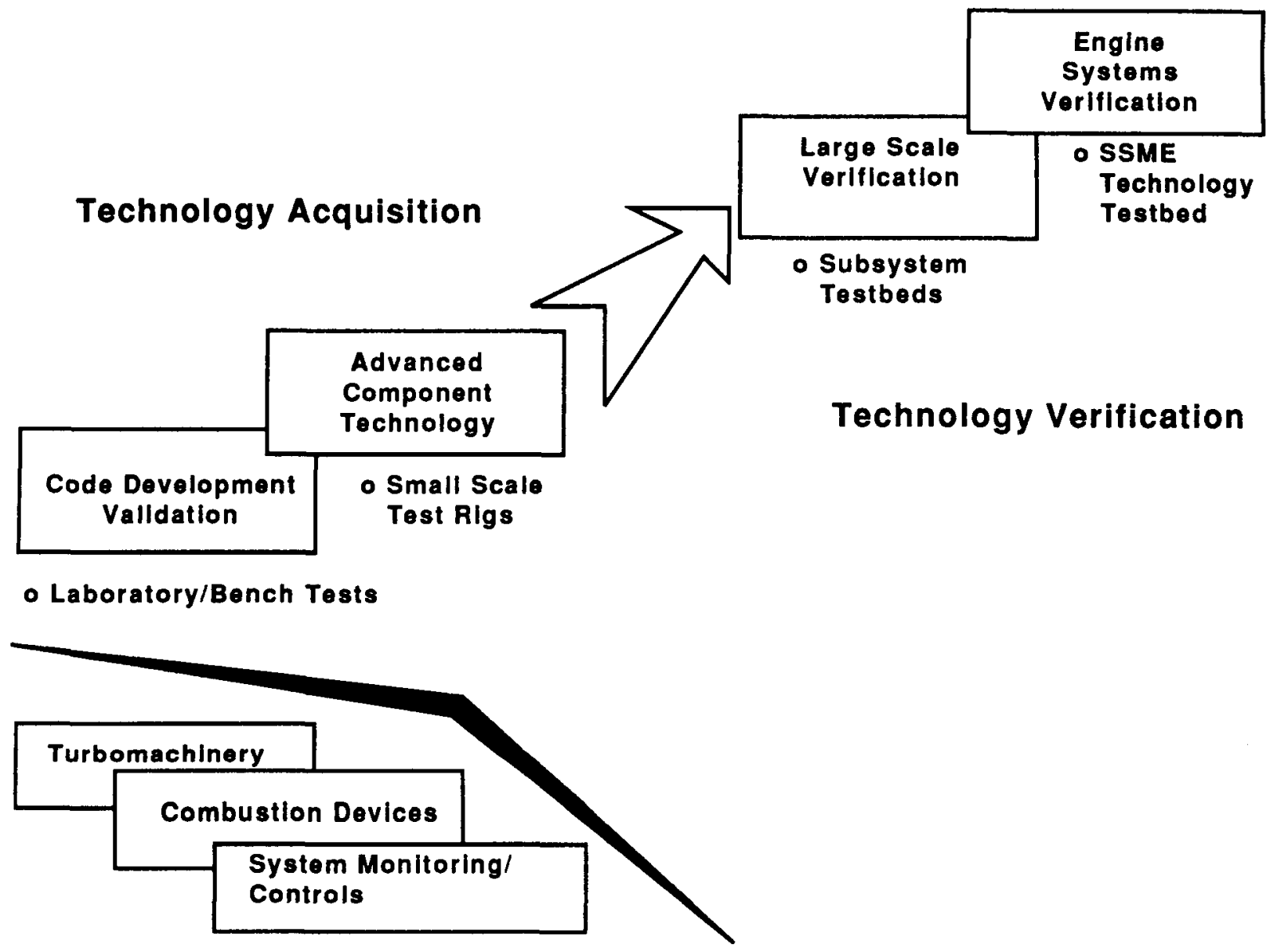

FIgure 2. CSTI Earth-to-Orblt Technical Strategy

products in a true engine environment. A nonflight SSME will initially be used as a test bed. The initial focus of the test bed program will be to operate a highly instrumented SSME to obtain baseline empirical data and to validate computer codes designed to analytically describe and model internal engine environments. Subsequently, technology products at the subcomponent level will be installed in the appropriate engine location for verification testing. Later, validated large scale turbomachinery and health monitoring and controls concepts will be integrated in the test bed to study system operation, interactions and dynamics.
CSTI Booster Technology

The Booster Technology element in CSTI will develop the technologies for alternative propulsion concepts to solid rocket booster motors on future launch vehicles. These alternatives will enable a safe abort option, the ability to tailor thrust, and the potential for enough additional impulse to avoid the need to operate the core engines at their highest power level. Thrust requirements for these engines will range from 750,000 to over $2,000,000 \mathrm{lbs}$. The pump-fed engine technology developed in the ETO Propulsion element will provide one approach to satisfying these requirements. However, two additional approaches which 
may provide further advantages will be examined in this element, a pressure-fed liquid rocket concept and a hybrid rocket concept.

Pressure-Fed Liquid (PEL) Program - The PFL concept has been used successfully in the past with very high reliability, man-rated storable propellant systems. In this concept, LOX and liquid hydrocarbon propellant flows will be induced by pressurizing the propellant tanks with an inert or benign gas, rather than relying on turbo-pumps. By eliminating the complexity associated with turbopumps, the PFL system offers potentially lower cost and higher reliability. However, these benefits will be at least partially offset by significantly higher propellant tank weights to sustain the higher tank pressures and also the weight and complexity of the pressurization system. An additional significant benefit of the liquid system is that the exhaust products of the LOX/hydrocarbon propellants will be more environmentally acceptable than conventional solid propellant exhausts. These propellants should also be available at a substantially lower cost than conventional solid rocket fuel.

The technology issues which will be addressed in the PFL program include the investigation of several concepts for tank pressurization. Conventional systems incorporate high pressure inert gas bottles which present a severe weight penalty. Alternatives involve gas generator systems which may use a catalyst to produce a LOX-rich or fuel-rich gas mixture, and heat exchangers to warm the pressurant gas.

Another significant area of study involves the combustion performance and stability of PFL systems. Since propellant pressure drop into the thrust chamber is minimized to reduce tank weight, these systems are susceptible to low frequency combustion instability. This involves an interaction between the combustion system and the propellant system. The low combustion pressures also raise issues associated with combustion efficiency, acoustic instability, and thrust chamber heat transfer and cooling.

The PFL program will begin with the development of analytical models of both low pressure combustion systems and tank pressurization concepts which address the technology issues identified above. Laboratory-scale test equipment will be used to acquire empirical data where necessary. These models and concepts will then be verified in large-scale component testing. Eventually, the systems level performance and feasibility of these technologies will be verified in a liquid rocket booster testbed which will include the engine, propellant tanks, and the pressurization system. These tests will focus on the system interaction, pressurization system control, and transient operation of PFL boosters.

Hybrid Program - A second approach to booster propulsion is a hybrid system which incorporates both liquid and solid propellants. In the broadest context of hybrids, either the fuel or the oxidizer may be a liquid (or alternatively a solid), and the liquid propellant is injected into the solid propellant motor where combustion occurs. In a typical hybrid concept, a liquid oxidizer (LOX) is injected into a rubber-based, solid propellant fuel. The solid fuel does not contain sufficient oxidizer to sustain combustion, thus the LOX flow can be modulated to throttle the engine or shut off to terminate thrust. The solid fuel offers the benefit of a somewhat higher energy density than liquid fuels, which leads to a smaller size vehicle. However, the energy density of the hybrid fuel combination is not as large as conventional solid rocket fuels, so the hybrid booster would be larger than a solid rocket motor. Since the solid fuel contains a minimum amount of oxidizer, it should be safer to manufacture and handle than conventional solid fuels which should lead to lower cost.

Technology issues associated with the hybrid include an oxidizer feed system which could be either pump-fed or pressure-fed. The pressurization studies conducted in support of the PFL element could contribute to this issue. Other issues are associated with the combustion process such as ignition, fuel grain composition, burning rate characteristics, mechanical properties, propellant tailoring, and oxidizer injection. Fuel case insulation materials and nozzle design and fabrication should also be studied.

The hybrid technology program will begin with a Concept Definition phase. In this phase, vari- 
ous hybrid concepts will be identified, critical technologies associated with each will be established, and a technology acquisition plan will be developed. The technology plan will be conducted in the second phase, Technology Acquisition, which will involve component and subscale tests, collection of a parametric data base, and model and code development. The third phase of the effort will verify the hybrid design methods and obtain a data base in a large scale motor test program. An important aspect of the technology program is to provide the confidence to scale systems up to the thrust level of large booster engines.

\section{BROJECT PATHEINDER.}

Project Pathfinder is a research and technology program that will enable a broad set of space missions, and directly supports the National Space Policy. Building on the foundation established by CSTI, Pathfinder will develop the emerging, innovative technologies that will make possible the bold exploratory missions identified in the studies of future civil space opportunities.

The program content is organized around four major thrusts: (1) Exploration, (2) Operations, (3) Humans-in-Space, and (4) Transfer

Vehicles. The specific elements associated with each thrusts are identified in figure 3 , and described in reference 7 . The propulsion technologies are incorporated in the transfer vehicles theme as Chemical Transfer Propulsion and Cargo Vehicle Propulsion. The titles are derived from the split mission concept in which high-thrust chemical propulsion is used on a manned vehicle, and lower-thrust electric propulsion is used on a cargo vehicle where performance is crucial and mission duration is less important.

\section{Chemical Transfer Propulsion}

The Chemical Transfer Propulsion Element will provide technologies for high performance, space-based engines for space transfer vehicles. These engines will perform a wide variety of space missions more efficiently and at reduced cost. In addition to the piloted Mars and Lunar missions, this element will provide substantially improved orbit transfer and re- turn capability to higher earth orbits (up to GEO) in support of Earth-observing missions as well as transfer to interplanetary trajectories for planetary science exploration missions.

These engines will utilize a high pressure expander cycle with liquid oxygen and liquid hydrogen propellants. Program goals include high performance over a wide throttling range, fault tolerant engine operation, in-space serviceability, maintainability and automated preflight operations. These systems will also be developed to provide the reliability and safety requirements commensurate with humanrating. Key technical issues include high heat transfer combustors, efficient turbomachinery capable of operation over a wide flow range, and system health diagnostics and controls. Research on critical technologies has been underway at the subcomponent level for several years, and this program will provide the opportunity to verify the design methods and advanced concepts in an integrated component testbed engine. Advanced mission-focused technologies will be identified and developed through component testing into a focused-technology test bed engine.

\section{Cargo Vehicle Propulsion}

The Cargo Vehicle Propulsion element will develop very high performance electric propulsion technologies for use in delivering cargo to support a piloted Mars mission and for outer planet robotic exploration missions. Two electric propulsion technologies are currently considered candidates for applications, ion and magnetoplasma-dynamic (MPD). This Pathfinder element will concentrate on the development of MPD systems and testing of ion and MPD thrusters. MPD systems have the advantage of being simple and compact, but only limited research has been done because they require megawatt-level power to perform effectively. Ion systems have been operated at reasonable efficiency, but substantial improvements are still needed. Long-term testing of both technologies is needed.

Key technology issues include MPD cathode lifetime and ability to create self-induced magnetic fields at megawatt power levels, and 


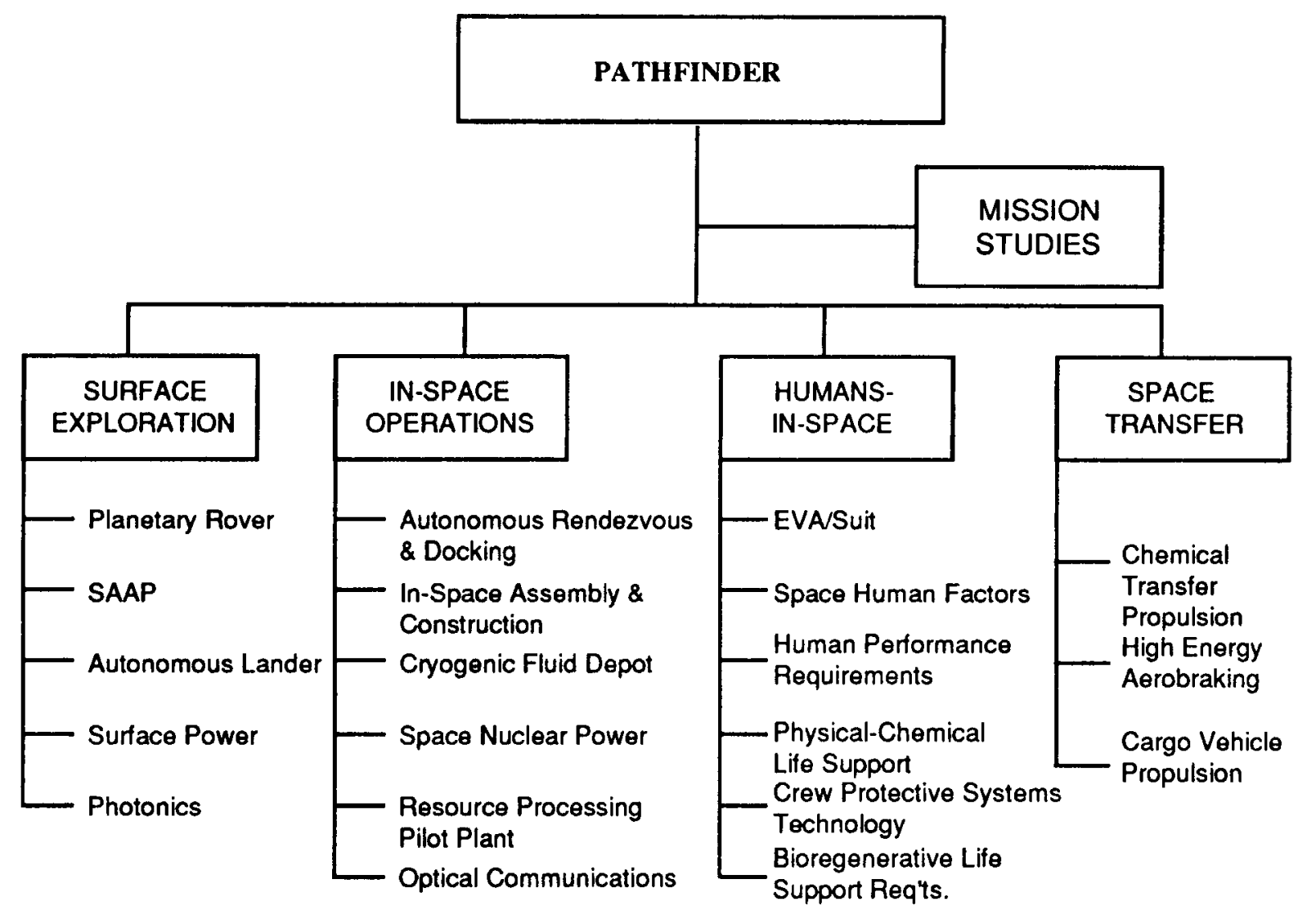

Figure 3. Pathfinder Program Elements

scale-up of ion systems is not well understood. Efforts to understand and improve component design and performance will lead to testing at near-megawatt levels in an adapted vacuum facility. These results will be used to guide a decision between ion and MPD concepts for further technology improvement. If appropriate facilities can be developed, long life testing of the selected system will be completed in a vacuum facility capable of withstanding the megawatt-level system power.

\section{Propulsion-Related Activities}

Two additional Pathfinder elements which are of critical importance to advanced propulsion technologies are the Cryogenic Fluid Depot and the Space Nuclear Power programs. The Cryogenic Fluid Depot effort will focus on the issues associated with handling, storing, managing and transferring cryogenic liquids in a zero-gravity environment. This capability will be indispensable for the large transfer vehicles needed to support the manned exploration missions.

The Space Nuclear Power element provides the NASA support for the SP-100 Program. This is a joint endeavor with the Department of Defense and the Department of Energy to develop critical technologies for a 100 kilowatt space nuclear reactor power source. In addition to the essential role of providing surface power for long duration manned exploration missions, the SP-100 technology is a necessary first step toward providing the electrical power needed to support high performance electric propulsion for cargo transfer operations. The specific impulse values of over 3000 seconds characteristic of electric propulsion systems can provide major benefits, but will require power systems ranging from hundreds of kilowatts to megawatts. 


\section{CONCLUDING REMARKS}

The National Space Policy sets ambitious and exciting long-range goals for space exploration and commerce. However, previous studies have shown that substantial investments in propulsion technology will be needed to support the range of opportunities which have been identified. The Civil Space Technology Initiative and Project Pathfinder are structured to provide the most critical technologies. CSTI will focus on near-Earth operations and launch capabilities. Pathfinder will provide transportation technologies for the exploration missions. Collectively, these programs can provide the technology base of verified design methods and data bases needed to design vehicles for the space missions of the next century.

\section{REFERENCES}

1. "FACT SHEET: Presidential Directive on National Space Policy," The White House, Office of the Press Secretary, February 11, 1988

2. "Pioneering the Space Frontier," The Report of the National Commission on Space, Bantam Books, New York, 1986.

3. S. K. Ride, "Leadership and America's Future in Space," A report to the (NASA) Administrator, August 1987.

4. "Space Technology to Meet Future Needs," Report of the Committee on Advanced Space Technology, Aeronautics and Space Engineering Board, National Research Council, National Academy Press, Washington, D.C., 1987.

5. "Exploration Studies Technical Report," NASA Office of Exploration, Washington, D.C., TM 4075, December 1988.

6. "Civil Space Technology Initiative: A First Step," NASA Office of Aeronautics and Space Technology, Washington, D.C., TM-100949.

7. "Project Pathfinder, Technology Benefits Assessment," NASA Office of Aeronautics and Space Technology, Washington, D.C., D-5031. 


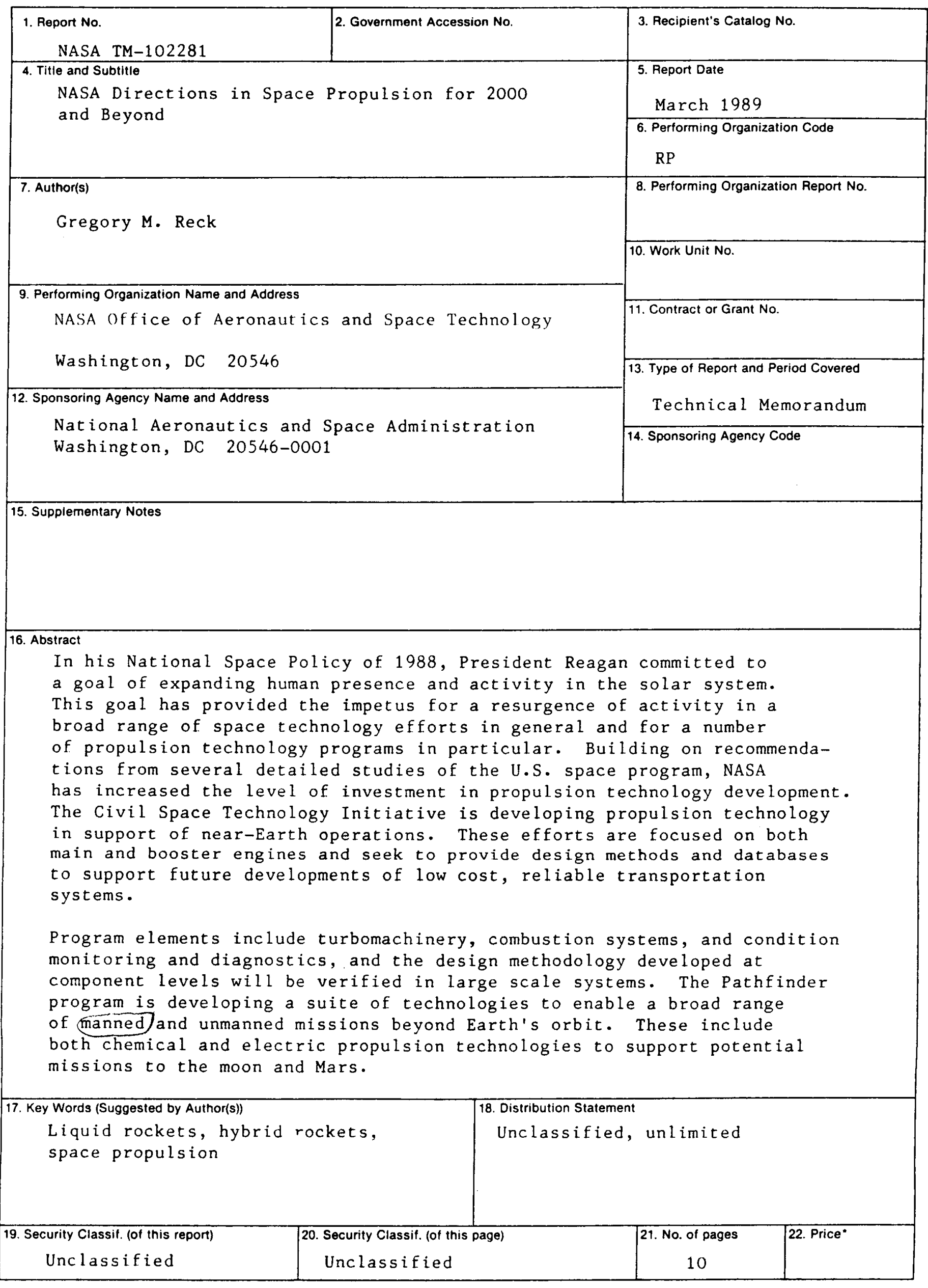

"For sale by the National Technical Information Service, Springfield, Virginia 22161 